\title{
Notes on the vocalizations of White-cheeked Honeyeater (Phylidonyris niger)
}

\section{Peter Boesman}

In the following we briefly analyze and compare voice of the two races of White-cheeked Honeyeater (Phylidonyris niger). We also try to quantify the extent of any vocal differences using the criteria proposed by Tobias et al. (2010), as a support for taxonomic review.

We have made use of sound recordings available on-line from Xeno Canto (XC) and Macaulay Library (ML).

An overview of vocabulary per race, illustrated with sonograms:

gouldi

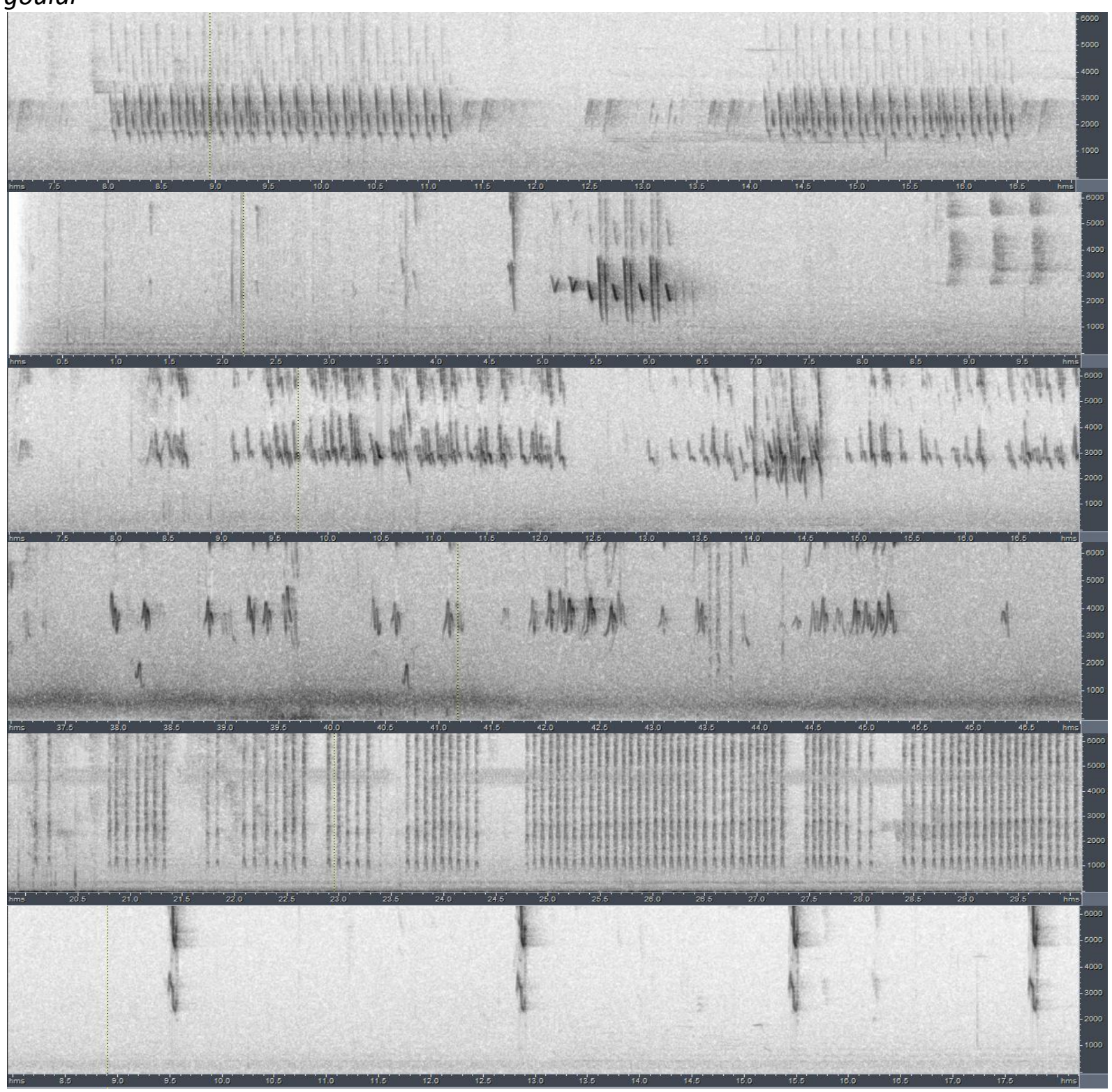




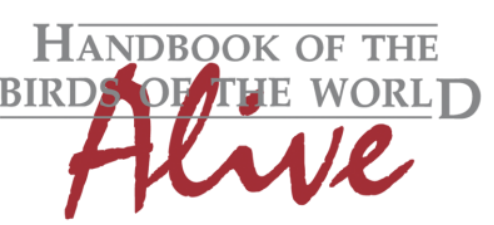

ORNITHOLOGICAL NOTES

nominate

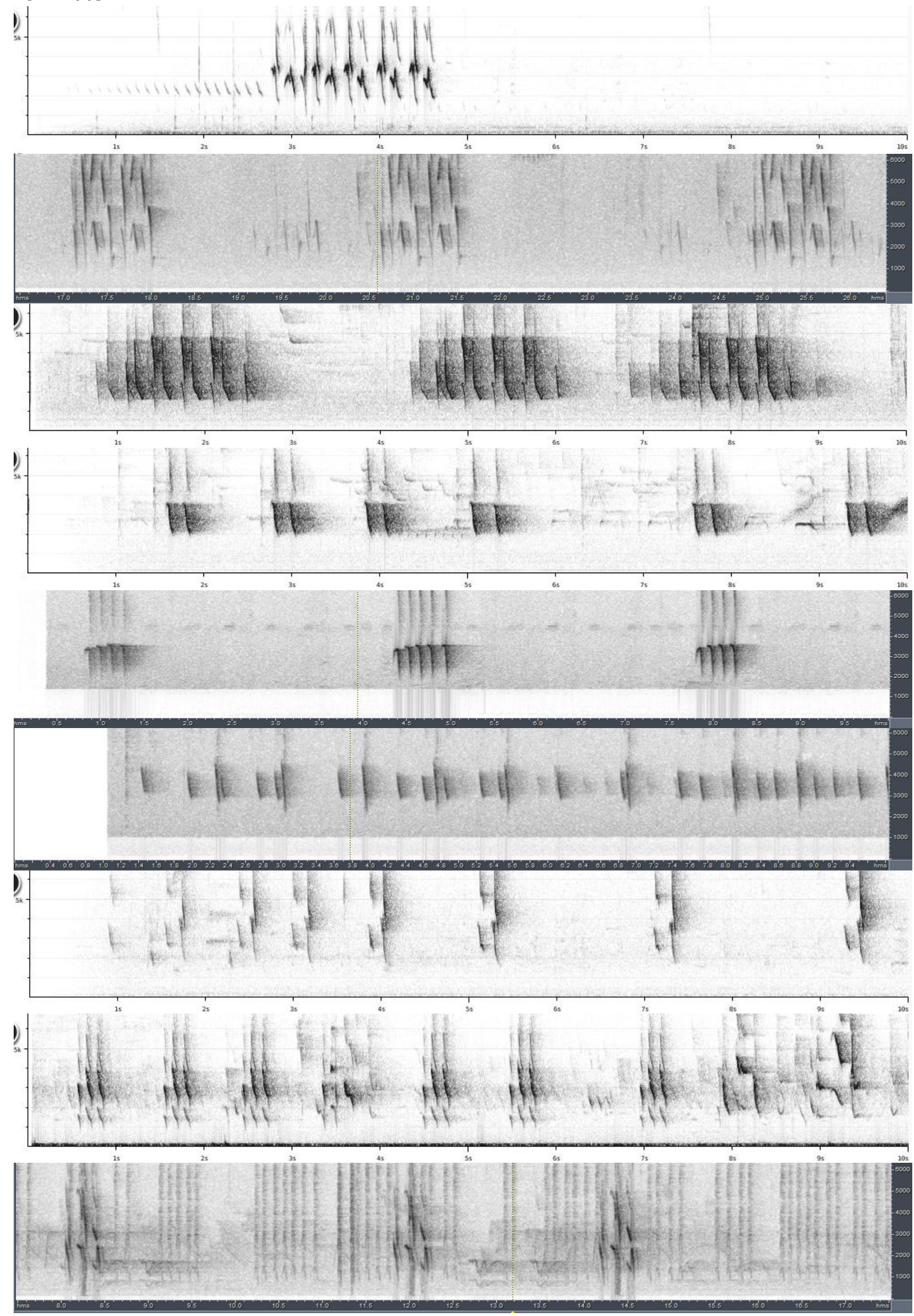



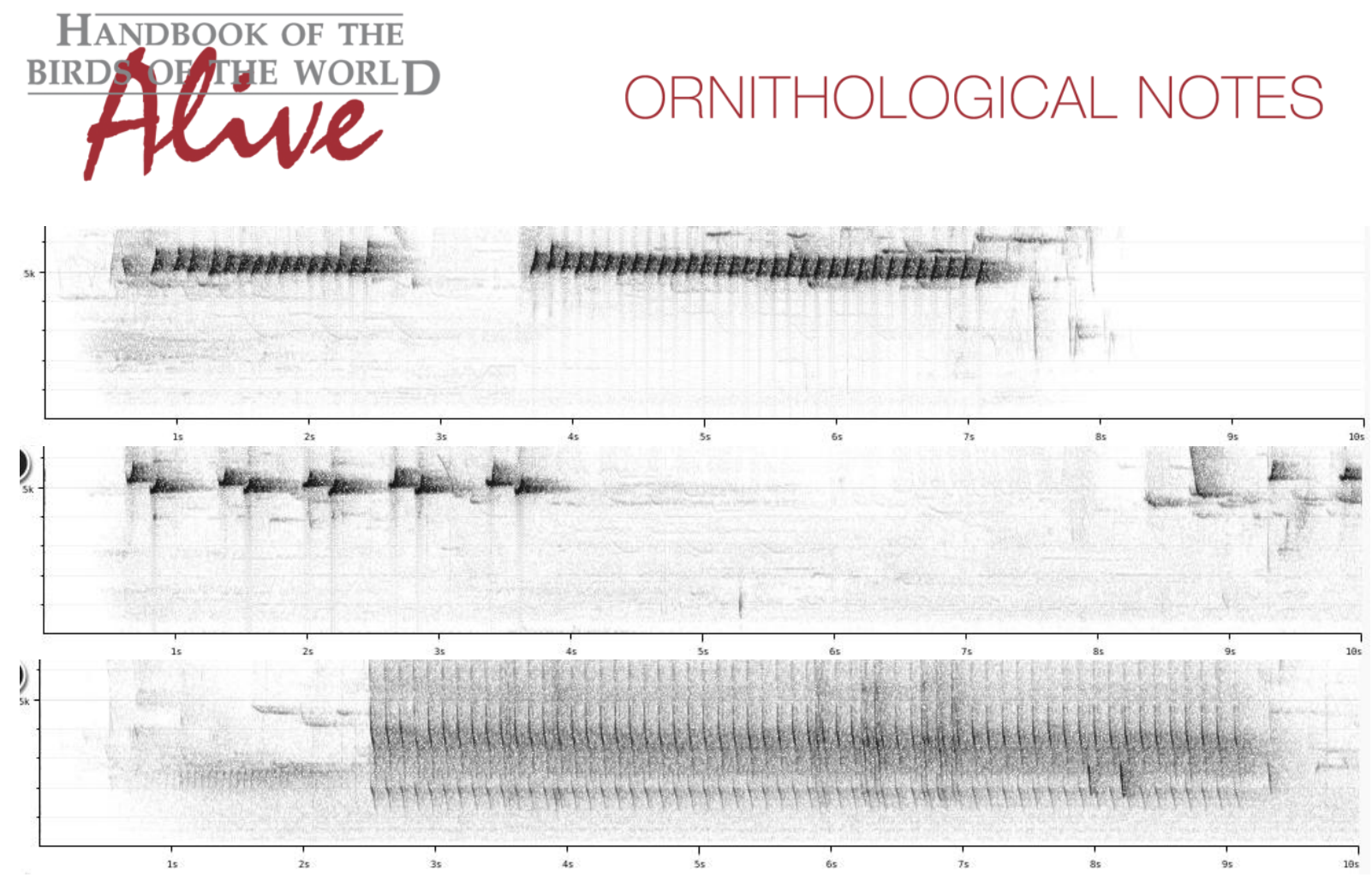

From the above examples, it is clear that vocabulary is quite extensive, in both races. With relatively few recordings available, and most recordings illustrating other sounds, it is somewhat risky to draw any conclusions on vocal differences between both races. It is however remarkable that none of the recordings of gouldi has a clear match with those of nominate. There is thus at least an indication of possible vocal difference (for which a score 1 could be allowed).

More recordings, especially of race gouldi, are needed to obtain a full overview of the vocabulary of both races.

This note was finalized on 8th July 2016, using sound recordings available on-line at that moment. We would like to thank in particular the sound recordists who placed their recordings for this species on XC and ML: Nicholas Allen, Marc Anderson, Emma Greig, Henk Krajenbrink, Greg McLachlan, Eliot Miller, Nick Talbot and the staff of Macaulay Library for forwarding the recordings of David Stewart.

\section{References}

Tobias, J.A., Seddon, N., Spottiswoode, C.N., Pilgrim, J.D., Fishpool, L.D.C. \& Collar, N.J. (2010). Quantitative criteria for species delimitation. Ibis 152(4): 724-746.

\section{Recommended citation}

Boesman, P. (2016). Notes on the vocalizations of White-cheeked Honeyeater (Phylidonyris niger). HBW Alive Ornithological Note 414. In: Handbook of the Birds of the World Alive. Lynx Edicions, Barcelona. (retrieved from http://www.hbw.com/node/1253815 on 6 December 2016). 